\title{
Biblioteca Pública, memória e educação patrimonial: a atuação interdisciplinar do bibliotecário e do turismólogo nos serviços educativos da Biblioteca Pública Benedito Leite
}

Maurício José Mora is Costa ${ }^{I}$

http://orcid.org/0000-0002-0759-9285

Klá utenys Dellene Guedes Cutrim ${ }^{I I}$ http://orcid.org/0000-0002-8668-4188

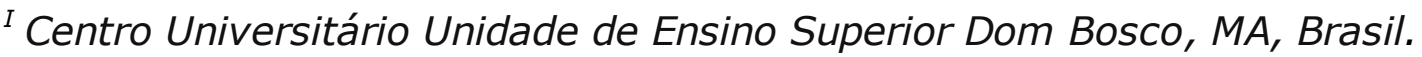
Mestre em Cultura e Sociedade. Docente do Centro Universitário Unidade de Ensino Superior Dom Bosco (UNDB).

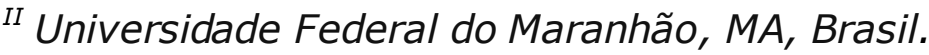

Doutora em Linguística e Língua Portuguesa pela Universidade Estadual Paulista Júlio de Mesquita Filho (UNESP). Professora do Departamento de Turismo e Hotelaria da UFMA e professora permanente do Programa de Pós-Graduação em Cultura e Sociedade (PGCULT/UFMA).

http://dx.doi.org/10.1590/1981-5344/4358

Investigação que objetiva relatar a prática interdisciplinar do bibliotecário e do turismólogo nos serviços educativos, bem como suas contribuições para a preservação da memória e do patrimônio cultural ludovicense e maranhense. Trata-se de uma pesquisa exploratória, de abordagem qualitativa, cujo corpus empírico foi composto por duas turismólogas e uma bibliotecária. Fez uso de entrevistas semiestruturadas para analisar como os serviços são planejados, quais as ambições da instituição em sua realização, as expectativas, bem como os desdobramentos deles nas ações da Benedito Leite em São Luís e no Maranhão. Aborda patrimônio, educação patrimonial, memória, bibliotecas públicas mediante diálogo com autores como Schneider (2018), Choay 
(2006), Wichers (2011), Horta, Grunberg e Monteiro (1999), Silveira (2012; 2014), Pollak (1989; 1992), Milanesi (2013), Nora (1993), Almeida Júnior (2013; 1997), Candau (2016), Sousa (2015), Flusser (1983), Cardoso (2013), dentre outros. Constata que a Benedito Leite busca cumprir seu papel na sociedade maranhense para além das práticas e demandas comuns às bibliotecas públicas. Reforça que a sensibilidade e atuação interdisciplinar entre a bibliotecária responsável pela direção e as turismólogas da BPBL imprimem em seus setores para planejar e realizar os serviços ofertados pela instituição são fundamentais para que as missões das bibliotecas públicas sejam concretizadas.

Palavras-chave: Patrimônio; Memória; Educação Patrimonial; Serviços Educativos; Biblioteca Pública Benedito Leite.

\section{Public Libraries, Memory and Heritage Education: the interdisciplinary practice of librarians and tourismologists in the education services of the Benedito Leite Public Library}

This research aims to relate the interdisciplinary practice of librarians and tourismologists in the education services, as well as their contributions to the preservation of memory and the cultural heritage of native people of São Luís and Maranhão. This is an exploratory research, with a qualitative approach, whose empirical corpus is composed of two tourismologists and one librarian. In order to do it we used semi-structured surveys to analyze how the services are planned, which are the ambitions of the institutions when making them, the expectations, as well as their repercussions in the actions of the Benedito Leite Library in São Luís and in the state of Maranhão. The research tackles issues such as heritage, heritage education, memory, and public libraries by means of 
discussions with authors such as Schneider (2018), Choay (2006), Wichers (2011), Horta, Grunberg e Monteiro (1999), Silveira (2012; 2014), Pollak (1989; 1992), Milanesi (2013), Nora (1993), Almeida Júnior (2013; 1997), Candau (2016), Sousa (2015), Flusser (1983), Cardoso (2013), among others. Finally, it ascertains that the Benedito Leite Library seeks to fulfill its role in the society of Maranhão, doing more than the usual practices and demands of a public library. It also reinforces that the sensitivity and the interdisciplinary collaboration between the librarian responsible for the administration of the library and the tourismologists of BPBL are present in their sectors to plan and perform the services offered by the institution, being also fundamental so that the missions of public libraries can be accomplished.

Keywords: Patrimony; Memory; Patrimonial Education; Educational Services; Benedito Leite Public Library.

Recebido em 11.04.2020 Aceito em 29.10.2021

\section{Introdução}

Analisar os serviços educativos da Biblioteca Pública Benedito Leite (BPBL) é desafiador, partindo-se da premissa de que é uma instituição cujas responsabilidades foram consagradas desde sua concepção em 1826. Fazendo-se presente na histórica do Maranhão, em especial de São Luís, a BPBL desvela os traços do desenvolvimento da capital, sua expansão, suas revoluções, suas lutas sociais, dentre outros elementos que fazem dela um importante espaço patrimonial, identitário e mnêmico. Desse modo, os serviços educativos da Benedito Leite, dentre os quais estão o serviço de atendimento ao usuário, a visita guiada (Circuito de Visita Cultural), a consulta de materiais raros, os projetos de ação, as intervenções junto ao acervo, as mediações educativas, a mediação de leitura e outros, serão analisados mediante diálogo com a metodologia de Educação Patrimonial (EP), bem como com os aspectos teórico-conceituais das categorias trabalhadas neste estudo, a saber: biblioteca pública, patrimônio cultural e memória.

Devendo favorecer o diálogo e a diversidade intercultural, assim como tornar possível o reconhecimento da herança cultural, a BPBL tornase espaço de múltiplas interações e intersubjetividades. Convergir tais significações e sentidos que a Benedito Leite assume em São Luís e no 
Maranhão evidencia sua relação com o patrimônio cultural - em seu entendimento expandido, material e imaterial - a memória e a identidade.

Dentre os diferentes caminhos pelos quais a Benedito Leite consegue cumprir seu papel enquanto biblioteca pública e centro cultural no Maranhão estão os serviços voltados para a comunidade, em especial os serviços educativos. Esses são essenciais para a dinamização do acervo, orientação dos usuários quanto aos produtos ofertados pela biblioteca, mas sobretudo ferramentas capazes de sensibilizar a população quanto ao acervo, ao patrimônio cultural ali abrigado, aos registros do conhecimento e a tudo aquilo que compõe a história, a memória e a identidade ludovicense e maranhense. Partindo de tais pressupostos, o presente estudo tem por objetivo analisar o trabalho interdisciplinar do bibliotecário e do turismólogo nos serviços educativos da Biblioteca Pública Benedito Leite (BPBL), bem como suas contribuições para a preservação da memória e do patrimônio cultural ludovicense e maranhense.

Trata-se de uma pesquisa exploratória, de abordagem qualitativa, cujo corpus empírico foi composto por três profissionais,as quais mantêm uma importante relação com a Benedito Leite e foram selecionadas mediante seus papéis na instituição. Uma vez que a pesquisa se dedica a analisar os serviços educativos desenvolvidos pela BPBL, foram incluídos na amostra duas turismólogas e uma bibliotecária, esta última responsável pela direção da instituição. A escolha foi motivada justamente por tratar-se dos responsáveis pelo planejamento e implementação dos projetos, ações, bem como dos serviços educativos.

Para tanto, procedeu-se a realização de entrevistas semiestruturadas, orientadas, por sua vez, por um roteiro de perguntas que permitiu às entrevistadas explanarem como os serviços são planejados, quais as ambições da instituição em sua realização, as expectativas, bem como os desdobramentos deles nas ações da Benedito Leite em São Luís e no Maranhão. Além disso, possibilitou inquirir questões relacionadas ao lugar da Biblioteca Benedito Leite no âmbito da memória, identidade e patrimônio cultural.

\section{Patrimônio e Educação Patrimonial}

Embora tenham passadas inúmeras décadas, a construção semântica da palavra patrimônio ainda é marcada por novas categorizações e apropriações. Igualmente às bibliotecas públicas, possuem um caráter diferenciado em relação às outras tipologias, múltiplas concepções e entendimentos.

Nesse sentido, Rocha (2018) assinala que o sentido de patrimônio foi se transformando no decorrer da construção histórica da sociedade, de modo que suas significações foram se modificando e ampliando com o 
passar dos anos. Grimaldi (2016) chama atenção para as relações diretas e assimilativas entre os conceitos patrimoniais e a própria cultura, que por muito tempo foram preconizadas e estão no auge da mercantilização. Acentua-se ainda, a apropriação desses conceitos por outras categorias, que o tornaram inerentes, por exemplo, à informação, elucidada pelo entendimento de patrimônio bibliográfico no campo da Biblioteconomia e Ciência da Informação, conforme explica Rodrigues (2016).

Schneider (2018) ressalta que a conceituação de patrimônio esteve fortemente relacionada com as ideias de herança e memória. Nora (1997, p. 12) já ressaltou essa proximidade, chamando de "constelação passional" a relação entre patrimônio cultural, memória e identidade, ou seja, categorias indissociáveis.

Etimologicamente, o termo patrimônio tem sua origem no latim patrimonium, aquilo que pertencia ao pai de uma família (LEMOS, 1981). Tal significado é corroborado por Choay (2006) e Schneider (2018), que corroboram que tal conceito é oriundo dos vocábulos greco-latinos "pater" e "nomos". A primeira referindo-se à paternidade, em seu sentido biológico, herança paterna (estando associada a bens, posses), enquanto a segunda, às leis, costumes e práticas de um determinado grupo social. Nessa acepção, patrimônio pode ser entendido como "[...] o conjunto de bens pertencentes ao pater, utilizada como sentido de herança, legado, isto é, aquilo que um pai deixa para seus filhos, portanto, patrimônio são o conjunto de bens de uma instituição, empresa, associação ou pessoas." (SCHNEIDER, 2018, p. 28).

Choay (2006) acentua que a contemporaneidade trouxe consigo um conceito ainda mais dilatado e "nômade", uma vez que a concepção de patrimônio fora requalificada, tendo que abraçar "[...] adjetivos genéticos, naturais, históricos, artísticos, culturais, materiais, intangíveis, virtuais e digitais, fazendo-o seguir um caminho diferente e retumbante, mas sem prejuízo do sentido fundamental." (GRIMALDI, 2016, p. 79). Percebe-se, portanto, a expansão dos entendimentos acerca dessa categoria, o que nos leva a refletir seus desdobramentos, a título de exemplo, no que tange às bibliotecas e às práticas dessas instituições, cuja prática tem como substrato os bens patrimoniais, cujas manifestações e expressões são múltiplas, antecipando, assim, uma discussão que viria décadas mais tarde.

Na busca por consolidar um conceito de patrimônio, Rocha (2018, p. 28) apresenta uma conceituação capaz de expressar a convergência das múltiplas dimensões desse domínio. Para a autora,

[...] pode ser entendido como patrimônio dos bens históricos e culturais, de caráter coletivo, ou seja, pertencente a um determinado grupo social com a pretensão de expressar um dado 
momento ou memória coletiva, servindo para construir e/ou reforçar a memória identitária desse grupo.

Logo, não se deve tratar o patrimônio como um domínio reducionista, mas deve-se assumir seu caráter material e imaterial, conforme explicitado por Rocha (2018). Oliveira (2018) complementa tal discussão, afirmando que a materialidade desse domínio não se reduz às produções artísticas e monumentais, assim como a sua imaterialidade que não se deve restringir às práticas cotidianas.

Nesse sentido, deve-se pensar as bibliotecas públicas como instâncias nas quais o patrimônio encontra abrigo e ressonância social, podendo ser apropriado pela sociedade e pelos indivíduos aos quais atende. As múltiplas especificidades desse patrimônio e suas distintas manifestações devem ser preconizadas tanto nas estratégias de catalogação e descrição, visando ao posterior acesso e uso, quanto nas metodologias de disseminação, reforçando a necessidade de refletir sobre as práticas de mediação desse patrimônio, ou seja, EP nas bibliotecas públicas, a ser tratado nas próximas seções.

Entende-se que o conceito de patrimônio, mesmo com o passar de séculos, ainda se encontra em constante mudança e expansão, cuja construção democrática e irrestrita deve contemplar os diferentes grupos, expressões, manifestações, linguagens, usos, materialidades e imaterialidades. E como bem reforça Oliveira (2018), tais entes são capazes de produzir e conferir relevância aos sentidos que o patrimônio galgou até a contemporaneidade.

\subsection{Educação Patrimonial}

Ao analisar brevemente a categoria Educação Patrimonial, pode-se, grosso modo, observar que ela é fruto da junção dos termos "Educação" e "Patrimônio", este último carregado de múltiplos sentidos, cuja maioria relacionam-se diretamente com a cultura (LIMA, 2014). Desse modo, é pertinente pensar tal categoria como iniciativas educacionais, tendo como foco o reconhecimento, a preservação e a valorização do patrimônio em suas mais distintas expressões e manifestações.

A EP tem sua gênese no modelo chamado Heritage Education que, segundo Durbin, Morris e Wilkson (1990), em sua obra intitulada $A$ Teacher's Guide to Learning from Objects. Surgiu em meados da década de 1970 na Inglaterra e Estados Unidos. Martins (2011) ressalta que tal metodologia é fruto das ditas "Pedagogias Renovadas", que marcavam justamente a transição entre os séculos XIX e XX, cujas práticas eram pautadas no contato direto com os objetos, e, conforme complementa Wichers (2011, p. 60), tinha por objetivo "[...] formar professores para o uso de objetos patrimoniais no ensino escolar." 
A EP se torna mais concreta com a chegada da década de 1980, mediante o desenvolvimento de ações mais direcionadas (MATOS, 2017; MARTINS, 2011). Conforme Almeida (2017), o lançamento do "Projeto Interação" fora considerado o primeiro programa estruturado em nível nacional, pautado no diálogo entre cultura popular, patrimônio e as escolas.

Inspirada no modelo da "Heritage Education", Maria de Lourdes Parreiras Horta apresenta a Educação Patrimonial visando a ressignificar as percepções e modos de lidar com os bens culturais, transformando as estratégias de transmissão dos conhecimentos atrelados a eles, tornandoos compreensíveis por um público "leigo" (CARDOSO, 2013; FLORÊNCIO et al., 2014).

Tornou-se explícita a expansão de iniciativas que visassem a dinamizar e estreitar a relação das pessoas com o patrimônio cultural, na perspectiva de que a preservação não fosse algo tão utópico e distante de suas realidades (FERNANDES, 2017). Nessa direção, a EP emerge como um caminho para colocar as comunidades, onde estão situados os bens, como protagonistas e principais guardiãs de seus bens patrimoniais. É fato que a população desconhece grande parte de seus patrimônios, logo é indispensável o desenvolvimento de ações educativas (CHAVES, 2012).

Segundo Chaves (2012), o Guia Básico de Educação Patrimonial trata-se de um documento que apresenta a metodologia e sugere uma série de vivências para distintos públicos e faixas etárias. Nesse sentido, tal metodologia é definida por Horta, Grunberg e Monteiro (1999, p. 6, grifo do autor) como:

[...] um processo permanente e sistemático de trabalho educacional centrado no Patrimônio Cultural como fonte primária de conhecimento e enriquecimento individual e coletivo. A partir da experiência e do contato direto com as evidências e manifestações da cultura, em todos os seus múltiplos aspectos, sentidos e significados, o trabalho da Educação Patrimonial busca levar as crianças e adultos a um processo ativo de conhecimento, apropriação e valorização de sua herança cultural, capacitandoos para um melhor usufruto destes bens, e propiciando a geração e a produção de novos conhecimentos, num processo contínuo de criação cultural.

Trata-se, então de "[...] um instrumento de "alfabetização cultural" que possibilita ao indivíduo fazer a leitura do mundo que o rodeia, levando-o à compreensão do universo sociocultural e da trajetória histórico-temporal em que está inserido." (HORTA; GRUNBERG; MONTEIRO, 1999, p. 5, grifo do autor). Logo, a EP expressa-se nas 
formas pelas quais os sujeitos podem ser sensibilizados culturalmente e, subsequentemente, se engajarem e construírem suas relações identitárias com o patrimônio cultural, oferecendo novos princípios incutidos de uma visão sociocultural dos usos, sentidos e significados dos bens patrimoniais na comunidade.

Nessa lógica, entende-se que os serviços educativos se constituem como um conjunto de estratégias que se ancoram no desenvolvimento de dinâmicas culturais e sociais que possibilitam a descoberta, a criatividade e a construção de conhecimentos, por sua vez apoiados na metodologia da EP. Pode-se destacar serviços que dinamizam a relação dos usuários para com esse múltiplo acervo, objeto do Serviço de Referência e Informação $(\mathrm{SRI})^{1}$ e dos serviços educativos realizados pela BPBL, a saber: a) Seção Materiais Especiais, responsável pela coleção de periódicos impressos (jornais e revistas); b) Setor de Obras Raras, Microfilmes e Manuscritos raros; c) Difusão Cultural; d) Seções de referência; e) Obras maranhenses; f) Seção Infantil da Biblioteca Pública Benedito Leite (Biblioteca Infantil Viriato Correa); g) Sistema Estadual de Bibliotecas Públicas do Maranhão (SEBP-MA); h) Visitas do Circuito de Visita Cultural da SECMA.

Tais seções da Benedito Leite são responsáveis pela dinamização das ações de mediação dos bens patrimoniais abrigados na instituição. Esses setores e atividades têm por objetivo sensibilizar culturalmente os indivíduos para o patrimônio cultural, ressaltando, assim, a visão inicial da alfabetização cultural indicada por Horta, Grunberg e Monteiro (1999), ao passo que a EP não se limita a letramentos e processos de alfabetização cultural, tampouco a simples identificação dos objetos ou fenômenos, mas a sua relação com a sociedade, sua natureza, seus contextos e estruturas simbólicas plurais nos quais estão inseridos.

\section{Bibliotecas Públicas e Memória}

A preocupação com o registro e preservação dos saberes, do conhecimento e de tudo aquilo que era vivenciado tinha como propósito evitar seu desaparecimento. Aspecto fundante das bibliotecas, preservar os registros do conhecimento tem sido uma de suas responsabilidades precípuas e, por conseguinte, manter viva a memória e a história são fatores que reforçam tanto o surgimento quanto a consolidação dessas instituições. Entra em evidência, então, a dicotomia "rememorar" e

\footnotetext{
${ }^{1}$ O setor da biblioteca responsável pelo atendimento direto aos usuários e a resolução de dúvidas é o Serviço de Referência. A mediação como um dos pilares do SRI, caracterizada pelo trabalho técnico realizado por todos os setores da biblioteca, objetiva a plenitude do processo de busca, recuperação e uso da informação (ALMEIDA JÚNIOR, 2013).
} 
"esquecer", que na perspectiva de Silveira (2012) constitui a construção discursiva que rege as ações humanas.

O processo memorial que reconstitui o passado parte justamente dos discursos culturais materializados nos acervos das bibliotecas, entendidas como organismos incumbidos - historicamente - de salvaguardar o patrimônio - em suas mais distintas expressões e manifestações - tornando possível o acesso a diferentes artefatos produzidos e acumulados pelos seres humanos, tornando-se lugares onde a memória se faz reconhecer (RODRIGUES, 2015; GOMES, 2014).

As bibliotecas trazem consigo forte apelo memorial, não apenas pela relação histórica estabelecida desde a Antiguidade, mas sobretudo por suas práticas estarem ancoradas na salvaguarda de materiais onde a história está registrada, ou seja, elementos que permitem a reconstituição da memória. Logo, é basilar compreender tanto os fundamentos teóricos acerca das noções de memória, quanto a relação dessa com as bibliotecas públicas. Embora o domínio da memória esteja diretamente relacionado com a identidade, a segunda não é uma categoria que apoia este estudo, portanto não será abordada em profundidade.

Partindo disso, Souza (2014, p. 98) nos diz que "[...] a memória é vista como a faculdade humana responsável pela conservação do passado, das experiências vividas." Silveira (2012) reforça que a memória, e, por conseguinte, a história humana são constituídas por associações não lineares entre as experiências vividas e o presente. Le Goff (2013) acentua que tais características conduzem a um arcabouço de funcionalidades psíquicas que possibilitam a atualização das impressões e informações pretéritas que 0 homem reproduz como passadas/experienciadas.

Pollak (1989) percebe a relação dos indivíduos com seu passado a partir de conflitos entre as perspectivas individual e coletiva. O austríaco defende que a memória individual é fruto da interação com o coletivo (POLLAK, 1989). A memória é entendida por ele como operação coletiva de acontecimentos e intepretações do passado, as quais se desejam salvaguardar e, como explica Pollak (1989, p. 7),

[...] se integra, como vimos, em tentativas mais ou menos conscientes de definir e de reforçar sentimentos de pertencimento e fronteiras sociais entre coletividades de tamanhos diferentes: partidos, sindicatos, igrejas, aldeias, regiões, clãs, famílias, nações etc.

As instituições e grupos sociais são entendidos por Pollak (1989) como os entes integradores da memória, ou seja, a coletividade é responsável por demarcar práticas, vivências, dentre outras ações sociais 
que virão a compor as lembranças. Nesse grupo, pode-se incluir também as bibliotecas públicas, cujo valor social fora reforçado ao longo deste estudo, entendida também como espaço de sociabilidade, interações e intersubjetividades (SILVEIRA, 2014).

Os elementos que compõem a memória assinalados por Pollak (1992) são vistos nas bibliotecas públicas, em especial na BPBL. A instituição firma-sena memória dos maranhenses não apenas por ser território de fatos importantes como os movimentos sociais, por ser palco de movimentos políticos, greves, carreatas, mas também por preservar a lembrança do jornalista Benedito Pereira Leite ${ }^{2}$ e por consagrar-se em um lugar presente nas rememorações dos cidadãos ludovicenses.

Esse fascínio e encantamento que as bibliotecas proporcionam, refletidos, por exemplo, na admiração que os cidadãos maranhenses têm pela Benedito Leite, pelas constantes menções à sua escadaria e imponência arquitetônica, vistas nas características neoclássicas de sua fachada ou pelo fato de a BPBL ter sido construída no ponto mais alto da cidade, na Praça do Pantheon -que fica no centro de São Luís e é semelhante ao Partenon de Atenas - , além de trazer elementos dos templos gregos (colunas gregas dóricas, jônicas e coríntias) (PEREIRA; CASTRO; RAMOS, 2016).

Vê-se uma relação diferenciada de significação entre patrimônio, memória e bibliotecas públicas. As bibliotecas públicas são basilares na operacionalização da memória, uma vez que seus monumentos/documentos/registros/imaterialidades permitem tanto a perpetuação dos testemunhos socioculturais, quanto direcionam e enveredam o futuro. A Benedito Leite, ao compor um acervo privilegiando os traços e a história do Maranhão, valoriza seus contextos sociais, suas crenças, seus valores, reafirmando sua intangibilidade. Sendo assim, seus produtos, seus serviços educativos convergem as dimensões simbólicas e espirituais, determinantes para a evocação das memórias individuais e coletivas.

Ressalta-se que as representações (materializadas em obras, peças, artefatos, patrimônios) podem se modificar e transformar-se a partir das relações que são estabelecidas com eles. Pode-se afirmar que são produzidos novos sentidos à medida que os indivíduos entram em contato

\footnotetext{
${ }^{2}$ Benedito Pereira Leite nasceu em Rosário (MA) no dia 4 de outubro de 1857, filho de Antônio Pereira Leite e de Ana Rita de Sousa Leite. Cursou o secundário no Colégio Imaculada Conceição, em São Luís, e bacharelou-se pela Faculdade de Direito do Recife em 1882. Foi também promotor público no município de Brejo e juiz municipal de Coroatá e Itapecuru, no interior maranhense, inspetor do Tesouro Público do Estado, e um dos diretores do jornal Debate. Para maiores informações, consultar o seguinte endereço eletrônico: http://cpdoc.fqv.br/sites/default/files/verbetes/primeira-republica/LEITE,\%20Benedito.pdf.

Acesso em: 11 abr. 2020.
} 
com os objetos dos acervos, por sua vez alvo das atividades de mediação (entenda-se serviços educativos para o patrimônio cultural, por exemplo), levam-nos a construir e reconstruir as compreensões de si mesmo e do meio onde estão inseridos.

Dessa forma, pode situar a memória como a faculdade responsável por trazer para "[...] o momento presente as experiências passadas, gerando a sensação ilusória de que é possível reavivar o que passou, tornando o passado uma presença acessível." (SOUZA, 2014, p. 104). Essa perspectiva é reforçada por Sarlo (2007) ao dizer que ela funda um presente mediante as relações que estabelece com o passado, oposição essencial para que as pessoas tomem consciência do tempo, como bem reforça Le Goff (2013).

Desse modo, reforça-se que a relação entre patrimônio cultural e bibliotecas está fundada, justamente, na capacidade que essas instituições têm de reunir, organizar e difundir os traços e evidências da cultura de um povo. Trazendo essa lente para a Biblioteca Pública Benedito Leite e o povo maranhense, cita-se seu papel não apenas como agente de salvaguarda dos bens materiais (livros, manuscritos, periódicos), mas como mediadora e caminho para que os indivíduos se apropriem de sua história.

Tal relação tem pertinência para a memória, tendo em vista que ela pressupõe a existência de um passado, fator basilar para que as relações e conexões ocorram. A memória só existe se existir um passado, logo as bibliotecas, os arquivos, os museus também são além de espaços que abrigam esses "gatilhos", locais onde os registros do conhecimento, "lugares de memória" são fontes para que as pessoas revisitem seu passado e apropriem-se dele.

Portanto, enquanto território de sociabilidades, a Benedito Leite tornou-se referência política e social, também por sua imponência arquitetônica na cidade de São Luís. Nesse sentido, Viveiros (1960) reforça a localização privilegiada da instituição, no ponto mais elevado da cidade, tal como o Partenon, e cercada por bustos de personalidades históricas emblemáticas do Estado, lembrando a acrópole helênica Atenas, "[...] da qual é em terras brasileiras a legítima representante a vetusta e gloriosa São Luís [...]" (VIVEIROS, 1960, p. 314). De encontro ao que diz Viveiros (1960), pode-se afirmar que é a partir desses contatos que os sujeitos históricos que ali transitem rememoram seu passado e projetam seu futuro e as ações para o seu desenvolvimento em diferentes perspectivas. 


\section{Os serviços educativos da Benedito Leite, a memória e o patrimônio maranhense:resultados e discussões do trabalho interdisciplinar do bibliotecário e do turismólogo}

A Benedito Leite, por estar localizada no centro de São Luís, está passível de receber diferentes tipos de pessoas, desde os visitantes voluntários - cidadãos ludovicenses, indivíduos que moram próximo à BPBL, turistas - chamados pelos profissionais da instituição de "demanda espontânea". Há visitantes fruto de agendamentos (provenientes de escolas, instituições, entre outras), bem como pesquisadores, por sua vez motivados pela busca da informação e de materiais bibliográficos. Destacam-se, ainda, os visitantes cuja motivação vai além dos livros, pois enxergam a biblioteca como espaço cultural e museal, em razão da própria expansão do conceito de biblioteca pública e a ressignificação de seus espaços.

Segundo as turismólogas e a diretora, o fluxo de visitantes à Benedito Leite é maior entre os meses de dezembro, janeiro e julho, essa informação é corroborada pelos relatórios mensais da BPBL. Dentre os principais componentes do Complexo Deodoro ${ }^{3}$, sem dúvidas a BPBL é um dos mais importantes, pois está no centro do conjunto urbano e após a reforma teve seu entorno todo redesenhado, colocando-a ainda mais em evidência no centro da capital maranhense.

Logo, como expoente do Complexo, a BPBL conquista um espaço não apenas como ponto favorável para o turismo, mas como centro cultural, dado a diversidade de atividades (serviço de atendimento ao usuário, a visita guiada, as intervenções junto ao acervo, as mediações educativas, a mediação de leitura, dentre outros) que oferece, por sua vez potencializados pela atuação interdisciplinar entre bibliotecário e profissionais do turismo, alvo de análise neste estudo.

Inicialmente, no tocante ao corpo técnico da BPBL, destaca-se que as profissionais participantes da pesquisa estão vinculadas à Secretaria de Estado da Cultura (SECMA).A Turismóloga 1 é formada em Turismo e Hotelaria, ocupa o cargo de Assessora Especial I, lotada na SECMA há 3 anos, e está na BPBL há 6 meses. A Turismóloga 2, também é formada em Turismo, ocupa o cargo de Assessora Técnica e atua na BPBL há 3 anos. A Diretora é graduada em Biblioteconomia e possui especialização

${ }^{3}$ O Complexo Deodoro é um conjunto localizado no Centro Histórico de São Luís, no Maranhão, compreendido por duas praças, o Panteon, Deodoro e as alamedas Silva Maia e Gomes de Castro (ROCHA; BORGES, 2021). Segundo Pereira (2020), o complexo é considerado um dos principais espaços livres públicos situado na região central ludovicense. Representa parte da história da cidade e já recebeu distintas denominações, tais como: antigo Campo do Ourique, Largo do Quartel e Praça da Independência. 
em projetos, programas, formação de leitores, gestão estratégica e MBA em Gestão Pública. Trabalha no estado desde 1992, tendo exercido diferentes cargos de chefia, chefias de divisões, sendo na gestão do Governador Jackson Lago designada para atuar na Benedito Leite, onde assumiu o cargo de Gestora Geral em janeiro de 2015.

Diante disso, observa-se como a expansão do entendimento de biblioteca pública alcança as ações do Governo do Estado do Maranhão, a partir da presença de profissionais de diferentes áreas atuando na Benedito Leite. Essa visão vai ao encontro da equipe multidisciplinar que atua na instituição, em seus mais diferentes setores. Ressalta-se que a busca por melhoria está fundada na construção coletiva entre os profissionais de distintas áreas.

A equipe multidisciplinar e interdisciplinar contempla profissionais não apenas da Biblioteconomia, mas da História, Informática, Turismo, em virtude da entrada da Benedito Leite no roteiro turístico ludovicense. Sendo assim, é essencial que profissionais específicos executem atividades que culminem no atendimento dessas demandas, cada vez mais específicas (ASSIS, 2018; PEREZ, 2015).

Dá-se prosseguimento com o primeiro bloco da entrevista junto aos profissionais, que trata da importância da Benedito Leite para o Maranhão e para o Brasil, com vistas a analisar a percepção que elas, enquanto responsáveis pelo planejamento e realização dos serviços que atendem a diferentes perfis, demandas e públicos na capital ludovicense. Para tanto, questionou-se: Qual o papel da Biblioteca Pública para o Maranhão e para o Brasil? As falas podem ser observadas no Quadro 1:

Quadro 1 - Qual o papel da Biblioteca Pública para o Maranhão e para o Brasil?

\begin{tabular}{|l|l|l|}
\hline \multicolumn{2}{|c|}{ Turismólogas } & \multicolumn{1}{|c|}{ Diretora } \\
\hline $\begin{array}{l}\text { [...] eu estou sentindo agora pela } \\
\text { plataforma, as pessoas vêm até a } \\
\text { biblioteca, e a gente pergunta "é a } \\
\text { primeira vez?", a maioria é a } \\
\text { primeira vez que tem vindo. }\end{array}$ & $\begin{array}{l}\text { biblioteca da forma ampla, que a } \\
\text { biblioteca não é apenas um local onde } \\
\text { ela vai apenas pesquisar no livro } \\
\text { físico. Mas ela é muito presente, ter } \\
\text { um momento desses de discussão }\end{array}$ \\
\begin{tabular}{l|l} 
Então, eu acho que com esse papel, \\
como eu estou te dizendo, de daca da Pessoa com Deficiência é \\
divulgação, aí, quem sabe começa a \\
ser plantado uma semente.
\end{tabular} & $\begin{array}{l}\text { funço de uma biblioteca pública. E de } \\
\text { um equipamento de cultura. }\end{array}$ \\
\hline
\end{tabular}

Fonte: Entrevistas (2019). 
As turismólogas comungam que a Benedito Leite constitui-se em um espaço de busca, leitura, material. Todavia não visualizam essa importância junto à comunidade, pois para elas a os visitantes não têm o hábito de ler, tampouco de dirigir-se com frequência às unidades de informação, fazendo-o quando têm alguma demanda de pesquisa, trabalho escolar, como foi observado nos registros de visita disponíveis nos relatórios da $\mathrm{BPBL}$, no entanto o prazer pela leitura não é percebido por elas. Contudo, têm observado um movimento de mudança e reaproximação dos ludovicenses com a BPBL.

A Diretora reforça o papel social que têm as bibliotecas públicas, incumbidas de formar cidadãos e preservar a memória, aspectos defendidos por Milanesi (2013), Nora (1993) e Almeida Júnior (1997), portanto são importantes espaços culturais emancipatórios, visto que o acesso à informação pode promover distintas transformações, bem como o exercício da cidadania.

Dialogando com as missões das bibliotecas públicas, é possível observar na fala da Diretora não apenas a expansão do conceito de bibliotecas públicas defendido por Milanesi (2003) e Mendes (2014), mas também a dimensão política da Benedito Leite ao promover debates de temáticas importantes para a sociedade maranhense, como as questões relacionadas à acessibilidade, a questões políticas, dentre outras. Com isso, afirma-se que as bibliotecas, em especial a BPBL são espaços de diferentes movimentos sociais, como ressaltado no Quadro 2, ao evidenciarem revoluções políticas, cujo ponto de encontro fora a Praça do Pantheon:

Quadro 2 - A BPBL e a Memória na fala das turismólogas e diretora.

Turismólogas

Greve de 1979, quando estava na luta pela meia-passagem, marcou a passagem de nossa história;

Referência para comício político, manifestações políticas na praça, movimentos sociais, porém sou contra devido os limites de uma biblioteca, o volume alto demais, o som alto, recordo também os governos de Roseana e Cafeteira, por fim a reforma da praça Deodoro.
Diretora

Além de tudo, nós somos um prédio com uma arquitetura clássica que é um prédio tombado. E aí, e a gente tem que preservar o imaterial também, que são essas tradições. Isso tudo o que está além da questão física, da leitura física. [...] Mas você não vê, a população, os vândalos depredando. É lógico, que é muito utilizada, ela vai sendo gasta. [...] Você não vê vandalismo assim do prédio. As pessoas têm um respeito muito grande. 
Fonte: Entrevistas e Questionários (2019).

Observa-se, a partir das falas das turismólogas e da diretora da Benedito Leite explicitadas no Quadro 2, como a instituição atua como um local mnêmico, reforçado por suas características arquitetônicas marcantes e sociabilidades na capital maranhense, por exemplo. O prédio da BPBL evoca inúmeras lembranças, como a cultura grega, pois conforme mencionado anteriormente neste texto, o prédio da instituição está situado em uma posição privilegiada e se assemelha às ágoras (PEREIRA; CASTRO; RAMOS, 2016), que serviam de espaço para reuniões populares dos gregos,tal como a própria Benedito Leite na Praça do Pantheon em São Luís, a qual se apresenta como território para manifestações, discussões, protestos públicos e ponto de encontro de famílias, moradores do centro, dentre outros.

Desse modo, o prédio da instituição possibilita a reconstituição das memórias individuais e coletivas (HALBWACHS, 2006; CANDAU, 2016), pois segundo Pollak (1992, p. 2), a memória deve ser entendida também, "[...] como um fenômeno coletivo e social, ou seja, como um fenômeno construído coletivamente e submetido a flutuações, transformações, mudanças constantes."

Ao passo que se mostra como ponto de encontro de memórias individuais, a Benedito Leite pode ser considerada como "marco de memória", ou seja, "pontos imutáveis". Como explicam Candau (2016) e Pollak (1992), são locais onde a memória se solidifica e se torna um referencial mnêmico e locus em que as memórias individuais encontram terreno para se estabelecerem. A BPBL tornou-se um espaço que possibilita aos ludovicenses voltar ao passado, reencontrar personagens históricos, dentre outras rememorações.

Nessa perspectiva, enquanto espaços privilegiados, cujas relações intersubjetivas proporcionam aos indivíduos encontrarem suas referências pessoais, suas histórias e memórias compartilhadas, os quais por sua vez permitem a construção de suas identidades, reforçam a atuação da diretora, turismólogas e demais profissionais da Benedito Leite na preservação de patrimônios e bens materiais, que em seus espaços revelam-se imateriais (SILVEIRA; MOURA, 2016; SILVEIRA, 2014).

Não sendo, a priori, um dos focos da BPBL, o Turismo tem sido algo explorado na instituição, não apenas por contar com profissionais de Turismo no corpo técnico, mas pelo fato de a maioria dos visitantes espontâneos serem indivíduos interessados nos aspectos que vão além do bibliográfico. Por receber inúmeras visitas de escolas, a Turismóloga explica que "[...] o nosso foco maior aqui é de atendimento e escolas. $E$ as crianças que não têm o hábito de ver a biblioteca, elas ficam 
encantadas, deslumbradas [...]" (TURISMÓLOGA 1, informação verbal, 2019).

Os projetos e ações da Benedito Leite para os diferentes públicos, como a atenção especial que a instituição tem com a acessibilidade, com o desenvolvimento de projetos transversais ao patrimônio cultural, com as atividades que recontam a história da cidade de São Luís, dentre outras, são capazes de reforçar tanto a expansão do conceito de biblioteca pública, cujas demandas postas à $\mathrm{BPBL}$, à medida que seus usuários e visitantes a enxergam como um centro cultural capaz de convergir práticas já consolidadas das bibliotecas bem como possibilitar múltiplas interações, diálogos, trocas, partilhas, ações culturais, portanto, centros de cultura (FLUSSER, 1983; MENDES, 2014; MILANESI, 2003).

Fato é que antes os visitantes tinham como principal interesse "[...] vir aqui, sentar e olhar o livro, ou então pegar emprestado. Hoje não, ela quer a biblioteca realmente como esse espaço de cultura." (DIRETORA, informação verbal, 2019, grifo nosso). Por se tratar de um centro cultural, as demandas refletem esse interesse pelas questões patrimoniais, materiais da Benedito Leite, quando essa busca se assenta no interesse em obras raras, periódicos antigos e imateriais, ao resgatar os fatos relacionados ao perímetro da instituição, os movimentos populares concentrados em sua entrada principal.

Observa-se que o interesse dos visitantes pela Benedito Leite e seus múltiplos espaços resgata a relação do patrimônio cultural com o passado e a memória do que ficou de herança, mas ao mesmo tempo também consiste na memória do presente. Porém, Araripe (2004, p. 114) pontua que "[...] temos um patrimônio que agrupa pessoas e acontecimentos que testemunham períodos vividos. São memórias que profissionais e instituições credenciam como patrimônio: preservando-os, recuperandoos e conservando-os." Desse modo, afirma-se que a BPBL assumiu um papel conferido por seus visitantes que a veem como lócus onde a memória estará segura e preservada, ou seja, seus patrimônios.

Dito isso, buscou-se analisar como são planejados os serviços educativos da Biblioteca Pública Benedito Leite, em função da complexidade de seus usuários e visitantes, bem como as demandas que tem que atender, dentre outras responsabilidades. Nesse intento, as depoentes foram indagadas acerca das estratégias de planejamento, programação, gestão e acompanhamento dos produtos e serviços ofertados pela BPBL, em especial os serviços educativos, objeto deste estudo, tais como o serviço de atendimento ao usuário, visita guiada (Circuito de Visita Cultural), consulta de materiais raros, dentre outros.

Tanto as turismólogas, quanto a Diretora destacaram a realização de planejamentos de todas as atividades, ações e projetos realizados pela Benedito Leite. Segundo a Diretora tudo está pautado na missão da BPBL, 
"formar leitores e preservar a memória bibliográfica do Maranhão", sendo assim, tudo que é executado é com esse intuito. Ela ressalta que,

[...] é uma biblioteca pública, e, é diferente de uma biblioteca escolar, de uma biblioteca universitária, de uma biblioteca especializada, porque aqui ela é aberta. Então o planejamento de uma biblioteca pública. Ele é um planejamento que tem que ser como todo o planejamento, mas ele tem que ser muito flexível. (DIRETORA, informação verbal, 2019, grifo nosso).

A fala da diretora ilustra a ciência que os profissionais têm da complexidade da BPBL, visto tratar-se de uma biblioteca pública, cujas características explicitam o desafio dessas ao serem organismos polivalentes e diferenciadas das demais tipologias de bibliotecas. Além disso, são públicas, pois, em sua maioria, são vinculadas ao poder público, e isso é bem pontuado na fala da Diretora e das turismólogas. A Turismóloga 2 evidencia que o planejamento é anual, no qual cada chefe de setor realiza o seu, em seguida todos são repassados para a direção, que por sua vez irá elaborar um plano unificado a ser encaminhado e aprovado pela SECMA.

A Turismóloga 1, complementa acentuando que a direção da BPBL avalia o que é pertinente, bem como a viabilidade das ações propostas, para poder enviar para apreciação do Secretário de Estado da Cultura. A Diretora enfatiza as questões orçamentárias, considerado principal desafio para a instituição, pelo fato de a BPBL não possuir dotação orçamentária,

A gente não tem um recurso que a gente lide. Mas esse recurso ele vem a partir do momento que você começa a apresentar que aquele seu trabalho é importante, que tem retorno. Então a gente faz essas ações pensando sempre na inovação, como a gente vai fazer para atrair, usando muita criatividade, porque o gestor público tem que ser muito criativo [...]. E sabendo que ele é flexível, várias coisas vão ser inseridas, outras tantas não vão acontecer. A gente tem que fazer sempre pensando, focando qual é o objetivo da biblioteca pública. (DIRETORA, informação verbal, 2019).

Segundo as depoentes, o planejamento das ações da Benedito Leite é complexo, perpassa uma série de reuniões entre os responsáveis de cada setor. As equipes precisam se articular para decidir suas pretensões para o ano vindouro, de modo que se selecionam as principais que irão compor o documento oficial, que por sua vez serão alvo de acompanhamento em termos de execução. Desde a manutenção dos equipamentos, como a máquina de digitalização, microfilmagem até os 
projetos de difusão cultural, tendo em vista que o retorno não deve estar centralizado apenas em São Luís, mas todo o Estado do Maranhão.

Como enfatiza a Diretora, "Então, é um o planejamento macro, que ele vai passar e ele vai ser encaminhado também para ser discutido junto com a gestão, da área de planejamento da secretaria, da Secretaria de Cultura." (DIRETORA, informação verbal, 2019). Almeida Júnior (2013) destaca que as questões orçamentárias são sempre um desafio para as bibliotecas, representando grande dificuldade tanto para a implantação, quanto para a avaliação de produtos e serviços, ou seja, uma questão política. No caso da BPBL, essas questões são ainda mais desafiadoras, em razão da complexidade dos serviços ofertados tanto na capital ludovicense, quanto nas cidades do interior do Maranhão, tornando suas ações dependentes desse orçamento, muitas das vezes, insuficiente.

Nessa conjuntura, entra em discussão o papel político e social da biblioteca e do bibliotecário, de buscar mais recursos para o pleno funcionamento da unidade de informação que gere, quanto contribuir para a efetivação de políticas públicas, exigindo do profissional formas e mecanismos de participação e atuação política, tão necessária. Todavia, não basta apenas uma mudança de postura do bibliotecário, mas um olhar diferenciado do Estado pela BPBL.

A Diretora aponta, também, sua mobilização para buscar recursos alternativos para realização de campanhas, projetos no interior do Estado, como por exemplo o "Dia D da Leitura" que mobiliza gestores de bibliotecas públicas, comunitárias e os Faróis do Saber. Ela reforça que são ações que dependem de orçamento, do contrário não podem ser realizadas. Desse modo, ratifica-se que o acesso à informação, aos bens patrimoniais e à cultura são também responsabilidades do Governo, viabilizado por meio de políticas públicas e incentivos às instituições culturais, dando condições para que bibliotecários, turismólogos, historiadores, dentre outros profissionais consigam garantir aos cidadãos tal usufruto.

Ainda, no tocante ao planejamento anual da Benedito Leite, ressalta-se que ele é pensado para sua plena efetivação, ou seja, os serviços não podem ser interrompidos, pelo contrário devem ser intensificados e aumentar a quantidade de pessoas atendidas. Por tratarse de uma biblioteca pública, a Diretora enfatiza que "você tem que administrar para todo mundo", ou seja, para um público altamente diversificado e plural (SUAIDEN, 2018). Uma vez que a instituição é promotora de transformação social, logo será através da leitura, do acesso à informação, ao conhecimento e o usufruto dos bens culturais e patrimoniais que a sociedade ludovicense se desenvolverá (ALVES, 2015).

Diante disso, pode-se afirmar que a Benedito Leite congrega uma série de responsabilidades, que por sua vez ampliam as demandas já 
postas à instituição. Levando em consideração os relatos das turismólogas, bem como da diretora, a BPBL é cobrada tanto pelos gestores estaduais - entenda-se SECMA e Governo do Maranhão - quanto por seus usuários, bem como outras instituições locais. Ao ser convidada, por exemplo, para compor conselhos, comissões e demais conglomerados, a instituição fica impossibilitada de cumprir com seu calendário anual.

Além disso, cabe destacar que a Benedito Leite, além das atividades anteriormente mencionadas, também é responsável pelo Sistema Estadual de Bibliotecas Públicas do Maranhão (SEBP-MA), devendo prestar auxílio para mais 93 (noventa e três) bibliotecas públicas do Maranhão. Implica um dos principais problemas para as bibliotecas, como aponta Almeida Júnior (2013), a falta de profissionais para operação das unidades de informação. É indispensável que essa questão seja revista pelo Governo Estadual, dado a sobrecarga de trabalho para os funcionários da Benedito Leite.

A percepção e a sensibilidade da direção e dos demais profissionais atuantes na BPBL para planejar e realizar os serviços ofertados pela instituição são fundamentais para que as missões das bibliotecas públicas sejam concretizadas. Todavia, reforça-se a necessidade de incentivo e políticas Estaduais para que essas ações tenham um alcance maior em São Luís e no Maranhão. De acordo com Almeida Júnior (2013, p. 87) "A biblioteca pública e suas atividades são entendidas como complemento, suporte e apoio da educação formal." Além disso, ressalta-se que as bibliotecas públicas podem contribuir em diferentes aspectos, não apenas nos pontos indicados pelo autor, visando a alcançar um maior número de indivíduos e a promover a transformação social.

Deve-se destacar que,por ser uma biblioteca pública, é essencial a atuação de profissionais de diferentes campos do conhecimento. Segundo Assis (2018) os resultados positivos em qualquer unidade de informação são resultantes do trabalho conjunto do bibliotecário com equipes multidisciplinares. Há tanto o enriquecimento da prática profissional, quanto dos produtos e serviços desenvolvidos. Tal perspectiva é corroborada ao destacar que tais equipes são justamente as mais criativas, pois é fruto da integração, portanto, resultam em habilidades e conhecimentos, que quando partilhados concretizam-se em atividades diversificadas (PEREZ, 2015).

A consciência multidisciplinar faz-se presente na fala da Diretora, quando indagada acerca das metodologias de abordagem, ela ressalta que é trabalho da Benedito Leite despertar nos usuários e visitantes a noção de pertencimento, que o espaço da biblioteca lhes pertence e é para seu uso, para que possam se desenvolver e crescer como cidadãos. Ela pontua que as estratégias utilizadas são pautadas na sensibilização da população quanto aos bens comuns abrigados na instituição. Para ela, é somente a 
partir disso que a comunidade reconhecerá e preservará o patrimônio arquitetônico, bibliográfico, dentre outros.

A Diretora é enfática ao dizer que não trata a biblioteca pública e suas ações como "receitas", tampouco se vale do discurso pautado em "características da biblioteca", pois para ela "[...] as bibliotecas são diferentes e cada uma tem uma forma de fazer. A gente tem uma forma. Mas assim só são metodologias diferenciadas para cada ação." (DIRETORA, informação verbal, 2019, grifo nosso). Observa-se que cada ação, cada projeto, cada serviço exigirá dos profissionais um método distinto, com vistas a favorecer a apropriação e uso da informação. Por exemplo, não se pode adotar o procedimento de uma atividade de intervenção infantil com um usuário que demanda informação utilitária, que por sua vez será distinta no setor de referência.

A fala da Diretora expande o que foi apontado pelas turismólogas, uma vez que a Benedito Leite é vista como um espaço de convergência de metodologias, o que de fato se espera de uma biblioteca cujo público é plural e diversificado. Tratar questões como patrimônio cultural, memória e identidade por meio de uma linguagem científica demais ou inacessível, implica usuários e visitantes que sairão sem a informação que lhes é necessária. As estratégias de mediação para o patrimônio devem visar ao cumprimento das missões da Federação Internacional de Associações e Instituições Bibliotecárias (IFLA, 1994), ratificadas pelo SRI e que culmine da transmissão de saberes, valores, conhecimentos e sane as necessidades informacionais de cada indivíduo que faz uso dos produtos e serviços (ALMEIDA JÚNIOR, 2013; GROGAN, 2007).

Entende-se e reforça-se que tal responsabilidade não é exclusiva dos bibliotecários, embora esses sejam intérpretes e mediadores da informação cultural e do patrimônio bibliográfico, mas sim fomentar para que o SRI, por exemplo, seja além de um setor, para que os serviços educativos sejam potencializados. Mas, para que se efetive, é indispensável o trabalho conjunto com os demais profissionais da instituição, inclusive as turismólogas, os historiadores, pedagogos, dentre outros. Tal perspectiva é reforçada por Felício (2014) ao ressaltar os ganhos que as bibliotecas tiverem com o incremento de tecnologias e Sousa (2015) ao destacar que as instituições de informação - bibliotecas, arquivos, museus, etc. - devam prestar serviços voltados à ampliação de seus usuários reais e potenciais, bem como cativar novos públicos, portanto, expandindo as responsabilidades das bibliotecas.

A interdisciplinaridade enquanto característica basilar das bibliotecas públicas, tal como explicitado por Milanesi (2003) ao tratá-la como centro cultural e por Flusser (1983) ao reforçaras diferentes possibilidades de ação cultural, ressalta o diálogo que tal instituição estabelece com outros 
domínios, em especial o patrimônio cultural, amplamente debatido neste estudo.

Segundo Sousa (2015), as bibliotecas públicas, em sua essência, congregam a proteção e a preservação da memória, portanto, suas missões estão fundadas na valorização e no reconhecimento dos bens materiais e imateriais. Logo, é possível afirmar que a educação para o patrimônio se faz necessária, uma vez que também consistem em instituições educativas.

O potencial mediador e educativo da Benedito Leite está explicitado em seus serviços educativos, ou seja, são ações voltadas para além do patrimônio bibliográfico. Com isso, é essencial analisar de que forma a instituição tem incutido as ações de educação patrimonial, e se de fato elas têm contribuído para o reconhecimento, preservação e valorização dos múltiplos patrimônios na instituição e fora dela. Para tanto, as entrevistadas foram questionadas acerca da EP nas atividades da BPBL, inicialmente acerca do entendimento que tinham sobre tal metodologia.

Todavia, quando indagadas acerca das múltiplas faces da EP na Benedito Leite, as turismólogas não conseguem visualizá-la de forma ampla na instituição. Para elas, trata-se de uma metodologia associada ao Turismo, portanto, enquanto turismólogas, elas não conseguem efetivar. Percebe-se que elas têm uma visão restrita da EP, que em sua essência é interdisciplinar, visto seu surgimento estar fortemente associado aos museus e galerias de arte, como enfatiza Cardoso (2013). Dialogando com Milanesi (2003), as bibliotecas públicas são multifacetadas, ou seja, centros culturais, portanto, capazes de trabalhar com a mediação para o patrimônio cultural, a partir da EP.

Baseada em processos educativos democráticos, a EP é determinante para a construção de conhecimento coletivamente, tendo em especial a Benedito Leite como território. A instituição assume a responsabilidade de proteger e difundir os bens patrimoniais da Maranhão, como bem enfatizado na fala da Diretora. Para ela, a educação patrimonial desperta o pertencimento dos cidadãos ludovicenses, e, por conseguinte, o senso de preservação e cuidado de algo que lhes pertence, bem como sua transmissão para as gerações futuras, "[...] para que os filhos, os netos, bisnetos também usufruam daquele patrimônio, como eu te falei que é geral, que pode ser uma música, uma dança, um Tambor de Crioula, um livro." (DIRETORA, informação verbal, 2019).

Com isso, pode-se afirmar que a EP amplia as ações desenvolvidas no SRI. Os serviços educativos desenvolvidos em tal setor, pautados em estratégias dinâmicas de difusão do patrimônio cultural, conduzem as bibliotecas públicas para um caminho capaz de fomentar, estimular, sensibilizar a preservação e valorização dos bens comuns, bem como o compartilhamento de saberes fundamentais para o estabelecimento de 
vínculos entre os visitantes, usuários, funcionários e cidadãos maranhenses.

\section{CONSIDERAÇÕES FINAIS}

Constata-se que a Benedito Leite busca cumprir seu papel na sociedade maranhense, para além das práticas e demandas comuns às bibliotecas públicas, uma vez que os diálogos com a literatura e discussões empreendidas neste estudo trataram-na como centro cultural. Como tal, deve promover o reconhecimento da herança cultural, bem como espaço de múltiplas interações e intersubjetividades. Por se tratar de uma instituição complexa, o desafio identificado nas falas da diretora e das turismólogas é justamente contemplar em um planejamento anual e de orçamento restrito, ações voltadas para os diferentes segmentos sociais do Estado. Todavia, reconhece-se que a sensibilidade que a direção e os demais profissionais atuantes na BPBL imprimem em seus setores para planejar e realizar os serviços ofertados pela instituição são fundamentais para que as missões das bibliotecas públicas sejam concretizadas.

Nesse sentido, os resultados da pesquisa demonstram o lugar da Benedito Leite na sociedade maranhense, enquanto espaço físico e simbólico de preservação da memória de um povo e de sua história, cuja função vai além da simples reunião de bens materiais informativos, à medida que se constitui um lócus de sociabilidade dos sujeitos, que fortalece suas identidades e contribui para o reconhecimento de suas raízes culturais.

Tomando por base a consciência que as profissionais investigadas têm da Benedito Leite, destaca-se a capacidade dessas em reconhecerem a relação que a instituição estabelece com os domínios patrimônio e memória, uma vez que se fizeram presentes em todas as falas. Além disso, observou-se que tais categorias são comuns nos fazeres da Benedito Leite, não havendo, assim, sua separação. Intrinsicamente, fazem-se presentes nos planejamentos, nos atendimentos, nos serviços de referência e informação, nos serviços educativos, bem como nas relações intersubjetivas, cujas ações da BPBL promove, ao buscar garantir - acesso igualitário aos bens patrimoniais em suas mais distintas expressões e manifestações, não se limitando ao patrimônio bibliográfico, que, embora carregado de simbolismo e imaterialidade, é apenas um recorte da rica cultura maranhense.

Com isso, acentua-se que não apenas os serviços educativos, mas os demais projetos desenvolvidos, planejados e implementados pela Benedito Leite, por sua vez balizados pela SECMA, acentuam os diferentes sentidos que seus usuários, visitantes, profissionais, ou seja, a população 
maranhense como um todo, estabelecem e atribuem aos patrimônios que compõe seus multifacetados acervos.

Diante disso, evidencia-se que a educação patrimonial se mostra como um importante mecanismo, que possibilita o reconhecimento, a identificação dos bens patrimoniais, mas, sobretudo, sensibiliza e desenvolve nos indivíduos o senso de preservação e conservação, aspecto essencial para uma instituição que resgata, recupera e retrata a história e a memória do Estado do Maranhão.

\section{Referências}

ALMEIDA JÚNIOR, Oswaldo Francisco de. Bibliotecas públicas e bibliotecas alternativas. Londrina: Eduel, 1997.

ALMEIDA JÚNIOR, Oswaldo Francisco de. Biblioteca pública: avaliação de serviços. Londrina: Eduel, 2013. 297 p.

ALVES, Mirian Viana. Patrimônio cultural e políticas de cultura: o caso de São João da Barra/RJ. 2015. 102 f. Dissertação (Mestrado em Políticas Sociais) - Universidade Estadual do Norte Fluminense Darcy Ribeiro, Campo dos Goytacazes, Rio de Janeiro, 2015.

ARARIPE, Fátima Maria Alencar. O patrimônio cultural e seus significados. Transinformação, Campinas, v. 16, p. 2, p. 111-122, maio/ago. 2004.

ASSIS, Tainá Batista de. Perfil profissional do bibliotecário: atual e desejado. In: RIBEIRO, Anna Carolina Mendonça Lemos; FERREIRA, Pedro Cavalcanti Gonçalves. Bibliotecário do século XXI: pensando o seu papel na contemporaneidade. Brasília, DF: IPEA, 2018. p. 13-31.

CANDAU, Joel. Memória e Identidade. Tradução Maria Letícia Ferreira. São Paulo: Contexto, 2016. 221 p.

CARDOSO, Rosemary Aparecida. Arqueologia musealizada e educação patrimonial: caminhos e desafios da transmissão do conhecimento nos museus recifenses. 2013. 223 f. Dissertação (Mestrado em Arqueologia) Universidade Federal de Pernambuco, Recife, 2013.

CHAVES, César Roberto Castro. Educação patrimonial no bairro do Desterro: estudos sobre os projetos de patrimonialização no Centro Histórico de São Luís - MA. 2012. 129 f. Dissertação (Mestrado em Cultura e Sociedade) - Universidade Federal do Maranhão, São Luís, 2012.

CHOAY, Françoise. A alegoria do patrimônio. Trad. Luciano Vieira Machado; São Paulo: Ed. UNESP, 2006. 
DURBIN, G.; MORRIS, S.; WILKINSON, S. A teacher's guide to learning from objects. London: English 4358Heritage, 1990.

FEDERAÇÃO INTERNACIONAL DE ASSOCIAÇÕES E INSTITUIÇÕES BIBLIOTECÁRIAS. Manifesto da IFLA/UNESCO sobre bibliotecas públicas. Haia: IFLA, 1994. 2 p. Disponível em:

https://archive.ifla.org/VII/s8/unesco/port.htm. Acesso em: 20 jan. 2019.

FELICIO, Joana Carla de Souza Matta. Serviço de Referência Educação (SRE) em Bibliotecas Universitárias: análise das práticas voltadas ao desenvolvimento da competência em informação de seus usuários. 2014. 223 f. Dissertação (Mestrado em Ciência da Informação) - Universidade Federal de Santa Catarina, Florianópolis, 2014.

FERNANDES, Simone Monteiro Silvestre. Ações de educação patrimonial em Ouro Preto - relato de experiência. Revista Memorare, Tubarão, v. 4, n. 1, p. 69-92, jan./abr. 2017.

FLORÊNCIO, Sônia Regina Rampim et al.Educação patrimonial: histórico, conceitos e processos. Brasília, DF: IPHAN, 2014. 65 p.

FLUSSER, Victor. A biblioteca como um instrumento de ação cultural. $R$. Esc. Bibliotecon. UFMG, Belo Horizonte, v. 12, n. 2, p. 145-169, set. 1983.

GOMES, Henriette Ferreira. A biblioteca pública e os domínios da memória, da mediação e da identidade social. Perspectivas em Ciência da Informação, v. 19, número especial, p. 151-163, out./dez. 2014.

GRIMALDI, Stephanie Sá Leitão. Memória da Ciência e da Tecnologia: preservação do Patrimônio Cultural Brasileiro. 2016. 160 f. Dissertação (Mestrado em Ciência da Informação) - Universidade Federal de Pernambuco, Recife, 2016.

GROGAN, Denis Joseph. A prática do serviço de referência. Brasília, DF: Briquet de Lemos Livros, 2007. 196 p.

HALBWACHS, Maurice. A memória coletiva. São Paulo: Centauro, 2006. $224 \mathrm{p}$.

HORTA, Maria de Lourdes Parreiras; GRUNBERG, Evelina, MONTEIRO, Adriane Queiroz. Guia Básico de Educação Patrimonial. Brasília: Instituto do Patrimônio Histórico e Artístico Nacional, Museu Imperial. 1999. 69p. 
LE GOFF, Jacques. História e memória. 7. ed. rev. Campinas, SP: Editora UNICAMP, 2013. 504 p.

LEMOS, Carlos A. C. O que é patrimônio histórico. São Paulo: Editora Brasiliense, 1981.

LIMA, Leilane Patrícia de. A arqueologia e os indígenas na escola: um estudo de público em Londrina-PR. 2014. 295 f. Tese (Doutorado em Arqueologia) - Universidade de São Paulo, São Paulo, 2014.

MARTINS, Luciana Conrado. A constituição da educação em museus: o funcionamento do dispositivo pedagógico museal por meio de um estudo comparativo entre museus e artes plásticas, ciências humanas e ciência e tecnologia. 2011. 390 f. Tese (Doutorado em Educação) - Universidade de São Paulo, São Paulo, 2011.

MATOS, Alexandre Pena. Educação patrimonial no contexto arqueológico: reflexões acerca das práticas educacionais. 2017. 142 f. Tese (Doutorado em História) - Pontifícia Universidade Católica do Rio Grande do Sul, Porto Alegre, 2017.

MENDES, G. F. As contribuições das políticas culturais na formação da agenda pública para a gestão das bibliotecas públicas municipais. 2014. 163 f. Monografia (Especialização em Gestão Cultural) - Universidade Federal da Bahia, Salvador, 2014.

MILANESI, L. A casa da Invenção: Biblioteca Centro de Cultura. São Paulo: Ateliê, 2003. 271 p.

MILANESI, Luís. Biblioteca. 3. ed. São Paulo: Ateliê, 2013. 120 p.

NORA, Pierre. Entre memória e história: a problemática dos lugares. Revista Projeto História, São Paulo, v. 10, dez. 1993.

NORA, Pierre. Les lieux de mémoire. Paris: Quarto Gallimard, 1997. v.1-3.

OLIVEIRA, Lenora Azevedo de. Patrimônio Cultural, Memória e Identidade: um estudo etnográfico sobre processos de interação de atores humanos com monumentos cívicos. 2018. 217 f. Tese (Doutorado em Ciências Sociais) - Pontifícia Universidade Católica do Rio Grande do Sul, Porto Alegre, 2018.

PEREIRA, Cleyciane Cássia Moreira; CASTRO, César Augusto; RAMOS, Roseli de Oliveira. O imaginário sobre a Biblioteca Pública Benedito Leite: alguns aspectos. Folha de Rosto, Revista de Biblioteconomia e Ciência da Informação, v. 2, n. 1, p. 67-82, jan./jun. 2016. 
PEREIRA, Marcio Rodrigo da Silva. Praça Deodoro, São Luís MA. Vitruvius, n. 239, p. 1-3, jun. 2020. Disponível em:

https://vitruvius.com.br/revistas/read/minhacidade/20.239/7764. Acesso em: 27 ago. 2021.

PEREZ, Dolores Rodriguez. Abordagens do trabalho em equipe: a prática nas bibliotecas da Pontifícia Universidade Católica do Rio de Janeiro. In: SEMINÁRIO DE INFORMAÇÃO EM ARTE, 4., 2015. Anais eletrônicos [...] Rio de Janeiro: REDARTE, 2015. 9 p. Disponível em: https://doity.com.br/media/doity/submissoes/artigo4f8841191ed974031da9e40f47034c889f541f5a-arquivo.pdf. Acesso em: 03 nov. 2019.

POLLAK, Michael. Memória, esquecimento, silêncio. Estudos Históricos, Rio de Janeiro, v. 2, n. 3, p. 3-15, 1989.

POLLAK, Michael. Memória e identidade social. Estudos Históricos, Rio de Janeiro, v. 5, n. 10, p. 200-212, 1992.

ROCHA, Nathália Christine Garcez; BORGES, Débora Garreto. Práticas cotidianas no espaço público tombado:uma análise do complexo Deodoro de São Luís - Maranhão. Brazilian Journal of Development, Curitiba, v.7, n.2, p. 16740-16769, fev. 2021.

ROCHA, Raquel Peres. Patrimônio cultural imaterial de Itaituba/Pará. 2018. 168 f. Dissertação (Mestrado em História) - Pontifícia Universidade Católica de Goiás, Goiânia, 2018.

RODRIGUES, Marcia Carvalho. Memória, patrimônio, bibliotecas nacionais e a construção da identidade coletiva. Em Questão, Porto Alegre, v. 21, n. 2, p. 243-262, maio/ago. 2015.

RODRIGUES, Márcia Carvalho. Patrimônio documental nacional: conceitos e definições. RDBCI: Revista Digital de Biblioteconomia e Ciência da Informação, v. 14, n. 1, p. 110-125, fev. 2016.

SARLO, Beatriz. Tempo passado: cultura da memória e guinada subjetiva. São Paulo: Companhia das Letras, 2007. 136 p.

SCHNEIDER, Luiz Carlos. O Patrimônio Cultural a partir do estudo da paisagem: o caso de Santa Cruz do Sul (RS). 2018. 363 f. Tese (Doutorado em Planejamento Urbano e Regional) - Universidade Federal do Rio Grande do Sul, Porto Alegre, 2018. 
SILVEIRA, Fabrício José Nascimento da. Biblioteca pública, identidade e enraizamento: elaborações intersubjetivas ancoradas em torno da Luiz de Bessa. 2014. 257 f. Tese (Doutorado em Ciência da Informação) Universidade Federal de Minas Gerais, Belo Horizonte, 2014.

SILVEIRA, Fabrício José Nascimento da. Biblioteca pública, memória e discursos identitários: uma leitura sócio-histórica dos depoimentos colhidos pelo Projeto Memória Oral da Biblioteca Mário de Andrade (BMA). In: ENCONTRO NACIONAL DE PESQUISA EM CIÊNCIA DA INFORMAÇÃO, 13., 2012. Anais eletrônicos [...] Rio de Janeiro: IBICT, 2012. Disponível em:

https://scholar.google.com/citations?view op=view citation\&hl=en\&user =9xVeSuAAAAAJ\&citation for view=9xVeSuAAAAAJ:4DMP91E08xMC.

Acesso em: 05 maio 2019.

SILVEIRA, Fabrício José Nascimento da; MOURA, Maria Aparecida. Biblioteca, Memória Institucional e Acesso Aberto à Informação: apontamentos teóricos e experiências desenvolvidas pela Universidade Federal de Minas Gerais. In: RIBEIRO, Anna Carolina Mendonça Lemos; FERREIRA, Pedro Cavalcanti Gonçalves (Org.). Biblioteca do século XXI: desafios e perspectivas. Brasília, DF: IPEA, 2016. p. 197-222.

SOUSA, Dora Susana Simões de. O serviço educativo em arquivos, bibliotecas, museus e centros de documentação: um estudo de casos implementados na Região de Aveiro. 2015. 163 f. Dissertação (Mestrado em Educação e Bibliotecas) -Universidade Portucalense, Porto, 2015.

SOUZA, Mariana Jantsch. A memória como matéria para uma identidade: apontamentos teóricos acerca das noções de memória e identidade. Revista Graphos, v. 16, n. 1, 2014.

SUAIDEN, Emir José. O papel da biblioteca pública na reconstrução da verdade. Ci. Inf., Brasília, DF, v. 47, n. 2, p. 143-152, maio/ago. 2018.

VIVEIROS, Jerônimo de. Benedito Leite: um verdadeiro republicano. São Luís: Academia Maranhense de Letras; Instituto Histórico e Geográfico do Maranhão, 1960. 340 p.

WICHERS, Camila Azevedo de Moraes. Patrimônio arqueológico paulista: proposições e provocações museológicas. 2011. Tese (Doutorado em Arqueologia) - Museu de Arqueologia e Etnologia, Universidade de São Paulo, São Paulo, 2011. 